\title{
Indications and outcomes of enterovesical and colovesical fistulas: systematic review of the literature and meta-analysis of prevalence
}

\author{
Stefano Granieri' , Francesco Sessa ${ }^{2,3}$, Alessandro Bonomi ${ }^{4,6}$, Sissi Paleino ${ }^{4,1}$, Federica Bruno ${ }^{1}$, \\ Andrea Chierici ${ }^{4,1}$, Ivano Massimiliano Sciannamea ${ }^{1}$, Alessandro Germini ${ }^{1}$, Riccardo Campi ${ }^{2,3}$, Michele Talso ${ }^{5}$, \\ Antonio Facciorusso ${ }^{7}$, Gianfranco Deiana ${ }^{5}$, Sergio Serni ${ }^{2,3}$ and Christian Cotsoglou ${ }^{1 *}$
}

\begin{abstract}
Background: Entero-colovesical fistula is a rare complication of various benign and malignant diseases. The diagnosis is prominently based on clinical symptoms; imaging studies are necessary not only to confirm the presence of the fistula, but more importantly to demonstrate the extent and the nature of the fistula. There is still a lack of consensus regarding the if, when and how to repair the fistula. The aim of the study is to review the different surgical treatment options, focus on surgical indications, and explore cumulative recurrence, morbidity, and mortality rates of enterovesical and colo-vesical fistula patients.
\end{abstract}

Methods: A systematic review of the literature was conducted according to PRISMA guidelines. Random effects meta-analyses of proportions were developed to assess primary and secondary endpoints. $I^{2}$ statistic and Cochran's Q test were computed to assess inter-studies' heterogeneity.

Results: Twenty-two studies were included in the analysis with a total of 861 patients. Meta-analyses of proportions pointed out 5, 22.2, and 4.9\% rates for recurrence, complications, and mortality respectively. A single-stage procedure was performed in $75.5 \%$ of the cases, whereas a multi-stage operation in $15.5 \%$ of patients. Palliative surgery was performed in $6.2 \%$ of the cases. In $2.3 \%$ of the cases, the surgical procedure was not specified. Simple and advanced repair of the bladder was performed in $84.3 \%$ and $15.6 \%$ of the cases respectively.

Conclusions: Although burdened by a non-negligible rate of complications, surgical repair of entero-colovesical fistula leads to excellent results in terms of primary healing. Our review offers opportunities for significant further research in this field. Level of Evidence Level III according to ELIS (SR/MA with up to two negative criteria).

Keywords: Colovesical fistula, Enterovesical fistula, Surgical management, Systematic review, Meta-analysis

\section{Background}

Enterovesical and colovesical fistulas (EVF, CVF) are an aberrant, pathological communication between the enteric tract and the bladder. They have different

\footnotetext{
*Correspondence: christian.cotsoglou@asst-brianza.it; cotsoglou@icloud.com ${ }^{1}$ General Surgery Unit, ASST Brianza, Vimercate Hospital, Via Santi Cosma e Damiano, 10, 20871 Vimercate, Italy

Full list of author information is available at the end of the article
}

etiologies such as neoplasms of the colon and the bladder, inflammatory diseases, pelvic radiation therapy, traumatic and iatrogenic injuries. Among them, the most common is represented by colonic diverticulitis which accounts for $65-79 \%$ of cases, whereas $10-20 \%$ of cases are due to cancer, most frequently colonic adenocarcinoma [1-3]. Men seem to be more affected than women with a male/female ratio ranging from 2 to $3: 1[4,5]$. 
Up to $90 \%$ of patients suffering from EVF or CVF experience pneumaturia and/or fecaluria [6-9]. Other frequent symptoms are suprapubic pain, dysuria, urgency, and frequency, abdominal tenderness, abdominal mass, weight loss, or cutaneous manifestations in case of Crohn's disease (CD).

Computed tomography (CT) with oral or rectal contrast, represents the gold standard for diagnosis $[5,8,10]$. A second phase with IV contrast is recommended. Other useful diagnostic tools are represented by colonoscopy and cystoscopy $[8,11,12]$. Both methods are ideal to investigate hollow viscous mucosa and allow biopsies to confirm the suspicion of a cancer-related origin of EVFs/ CVFs.

Another useful diagnostic technique is represented by magnetic resonance (MR) especially when the underlying cause of EVF/CVF is Crohn's disease. Its high sensitivity and specificity in the diagnosis of complex intrabdominal and perianal fistulas is well established [12, 13]; therefore, in the presence of inflammatory bowel diseases it should be preferred over CT.

The treatment of entero-colovesical fistulas is eminently surgical $[11,14]$. Once the eventual abdominal fistula-related sepsis has been resolved with broad spectrum/targeted antibiotic therapy and bladder decompression through a Foley catheter, the primary treatment option is the closure of the fistula. Nonoperative management has been advocated for patients unfit for surgery, with mild symptoms, or those who decline surgical indication [15].

Despite a wide spectrum of open and laparoscopic surgical options, a lack of consensus concerning the timing, modalities, and optimal surgical strategy, based on the etiology of the fistula, still exists.

The present study aims to review the different surgical treatment options and to focus on surgical indications. To the best of our knowledge, this is the first meta-analysis in exploring cumulative recurrence, morbidity, and mortality rates of EVF and CVF patients.

\section{Materials and methods}

\section{Search strategy}

A systematic review of the English-language literature was performed according to PRISMA and AMSTAR guidelines [16, 17]. The Medline, Scopus, Cochrane Library and Web of Sciences databases were screened without time restrictions, up to August 10th, 2020. Articles without free full text available were searched through the digital library of the University of Milan, University of Florence, and through direct contact with authors. Handsearch of bibliographies of included studies and previous reviews on the topic was also performed to include additional relevant studies according to our selection criteria.
Two investigators (SG, FS) carried out the literature search independently.

\section{Primary and secondary endpoints}

The main aim of this review is to explore the effect of surgical treatments of colovesical and enterovesical fistulas and to summarize the current surgical indications. The primary outcome is represented by fistula recurrence, which is considered an indirect measure of primary healing of the fistula. The secondary outcome is represented by postoperative morbidity and mortality rates.

\section{Inclusion criteria}

We have included studies reporting surgical management of colo-enterovescical fistulas. Both clinical and radiological confirmation has had to be mentioned to deem the study eligible for the review. Benign aetiologies such as postoperative, iatrogenic, inflammatory (Inflammatory Bowel Disease, diverticulitis), and post-radiation therapy, as well as tumor related colovesical/enterovesical fistulas, have been considered.

A specific population (P), intervention (I), comparator $(\mathrm{C})$, outcome $(\mathrm{O})$, and study design (S) (PICOS) framework was specified to define study eligibility, as recommended [16]. In particular, the following criteria were outlined:

Population $(P)$ patients with a clinically and radiologically confirmed diagnosis of colovesical or enterovesical fistula;

Intervention (I) surgical management of the fistula;

Comparison $(C)$ any other non-surgical treatment (this criterion was not mandatory for inclusion of the studies in this review);

Outcomes $(O)$ primary healing of the fistula;

Study design (S) randomized-controlled or prospective/ retrospective cohort studies and case series with more than 10 patients.

\section{Exclusion criteria}

Studies including only patients managed conservatively or with insufficient reporting of the PICOS criteria were excluded. Similarly, studies including pediatric patients ( $<18$ years), with a mean/median follow-up (FUP) lower than 3 months, non-English language written, and previously published reviews were not deemed eligible.

\section{Systematic review process}

Mendeley reference software (Mendeley Ltd, London, UK) was used to identify and remove duplicates among identified records. After the exclusion of duplicates, three independent reviewers (SP, FB, AC) screened titles and abstracts. An a priori developed screening form was created to guide study selection. 
Disagreements were solved by a third party (IS), who supervised the systematic review process. Case reports, book chapters, editorials, conference abstracts, preclinical studies, previous reviews, and articles not related to the primary endpoint of this review were excluded.

\section{Data extraction and assessment of included studies}

Data were extracted independently by two authors (SG, $A B)$. The following summary data for the included studies were retrieved: name of the authors, year of publication, type of study, demographic data, etiology and type of fistula, diagnostic methods, surgical approach and management, FUP duration, recurrence, morbidity and mortality rates.

In case of disagreement, a further reviewer (AG) helped resolve the disagreement through discussion.

Two authors (SP, AF) independently assessed the quality of evidence provided by each study using the Oxford Center for Evidence-Based Medicine scoring system [18].

\section{Statistical analysis}

The primary outcome measure was represented by the proportion of patients with EVF/CVF recurrence after surgery. A random-effects model based on generic inverse variance method was built to assess the impact of heterogeneity on results. The presence of outliers was investigated, and their effects sizes excluded.

Heterogeneity between studies was quantified by $\mathrm{I}^{2}$ statistic and Cochran's Q test; cut-off values of 25, 50, and $75 \%$ were considered as low, moderate, and high, respectively [19]. Sensitivity analysis was performed using the leave-one-out method and Baujat plot was built to visually inspect studies overly contributing to heterogeneity.

Since our systematic review included studies published some time ago as well as recent pieces of evidence, we wanted to explore the effect of surgical practice improvement over time on fistula recurrence through metaregression analysis.

Funnel plots were developed to explore publication bias and Egger's test of the intercept was used to quantify funnel plots asymmetry. Duval \& Tweedie's trim-and-fill method was adopted to estimate and adjust for the number and outcomes of missing studies each time Egger's test demonstrated significant asymmetry. P-curve analysis was performed to confirm the results of the aforementioned publication bias assessment.

Statistical analysis was conducted with $\mathrm{R}$ statistical software (The Comprehensive $\mathrm{R}$ Archive NetworkCRAN, ver. 4.0.0 × 64) [20], using "meta", "metafor", and "dmetar" packages [21-24].

\section{Results}

The PRISMA flow diagram reporting the systematic review process is shown in Fig. 1.

Overall, 2314 articles were preliminarily identified by the literature search. Afer the exclusion of duplicates, titles and abstracts of 2252 records were screened. Fifty four articles were assessed for eligibility. Finally, 22 studies were included in qualitative and quantitative synthesis [2, 9-12, 25-41]. All of them were retrospective. Most of the excluded studies were deemed not eligible due to insufficient reporting of follow-up data, inclusion of pediatric patients, and mixed results with other types of enteric fistulas. Adjusted observational studies were not available, however the cohorts of the included studies were quite similar for principal confounders (age, underlying pathology, comorbidities).

In total, 861 patients undergoing surgery for EVF and/or CVF were included in the study. The male/ female ratio was $4: 1$ and the mean age was 58.7 years. Seven studies reported mean FUP time with an average of 53.6 months; one study reported a FUP range of 2-108 months; finally, the median FUP of the remaining studies was 34 months. Table 1 summarizes patients' characteristics.

The most frequent etiology of EVF/CVF described was a benign disease, with diverticular and Crohn's diseases accounting for $60.2 \%$ (519 patients) and $27.5 \%$ (237) of all cases respectively. Malignant diseases (mainly colorectal cancer; but also, bladder and prostate cancer) accounted for $6.5 \%$ of all cases (56 patients). Among other causes, appendicitis, trauma, radiation and iatrogenic lesions comprised a total of 21 cases. Only one study (Munoz 1998) did not report adequate details regarding EVF or CVF etiology.

The diagnostic methods most frequently adopted were CT, barium enema, and cystoscopy, which were used on average in $62.5,62.6$, and $59 \%$ of cases respectively. Further details about diagnostic procedures are available in Additional file 1.

\section{Primary outcome}

No outliers were identified. The meta-analysis of proportions pointed out a $5 \%$ recurrence rate of the fistula (95\% CI 3.37-7.32). $\mathrm{I}^{2}$ statistics revealed the presence of low heterogeneity $\left(\mathrm{I}^{2}=14.8 \%\right.$; $\left.\mathrm{p}=0.26\right)$ (Fig. $\left.2 \mathrm{~A}\right)$.

\section{Secondary outcome}

Only 19 studies recorded information regarding postsurgical morbidity ranging from $6.6 \%$ up to $45.5 \%$. The meta-analysis of proportions pointed out a $22.2 \%$ overall complication rate $\left(95 \%\right.$ CI 17.04-28.51). $\mathrm{I}^{2}$ 


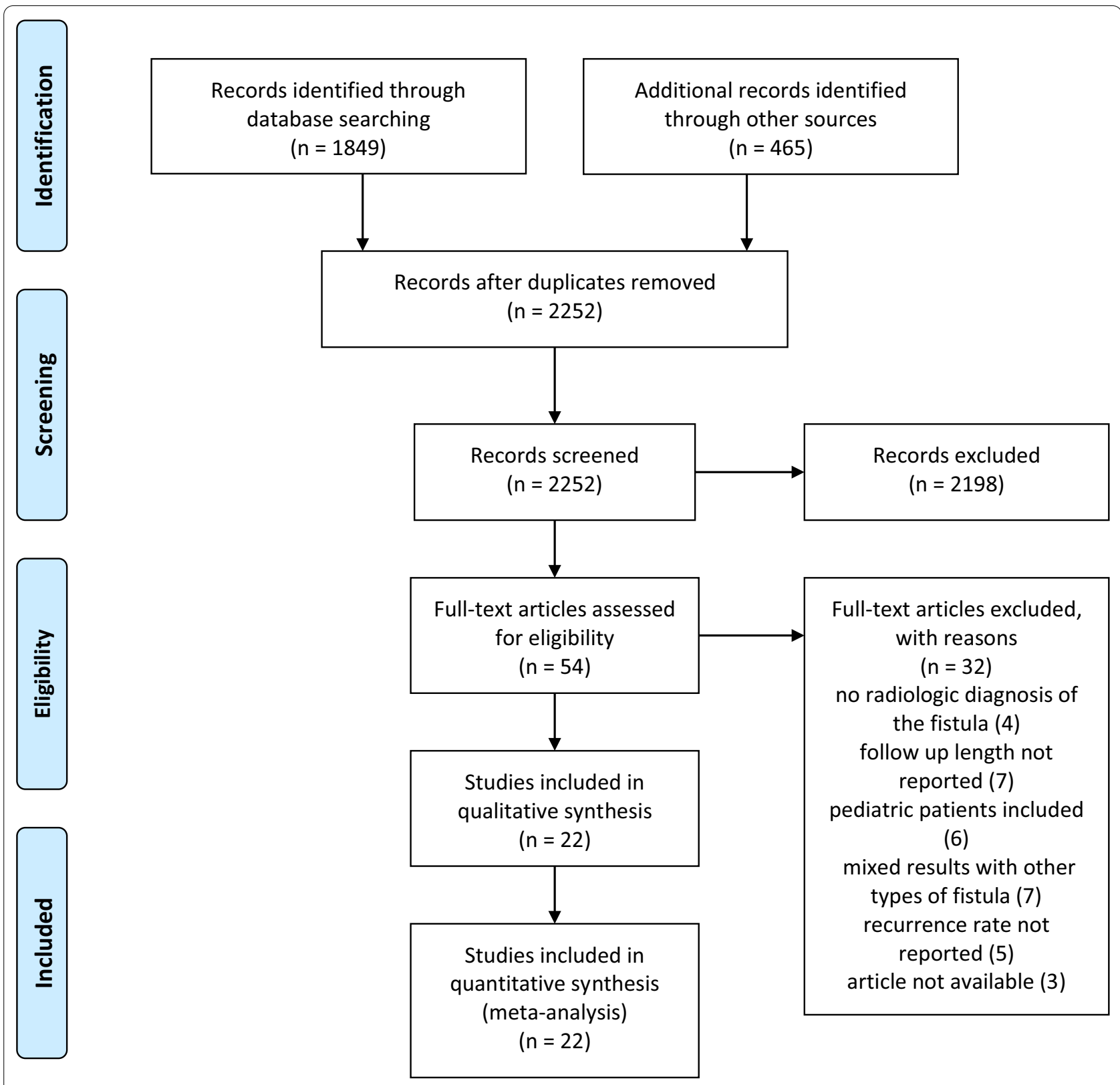

Fig. 1 PRISMA flow diagram of selected studies

statistics revealed the presence of moderate heterogeneity $\left(\mathrm{I}^{2}=64.6 \%\right.$; $\left.\mathrm{p}<0.0001\right)$ (Fig. $\left.2 \mathrm{~B}\right)$.

Nineteen studies reported data regarding postoperative mortality: 10 of them reported no postoperative mortality, whereas in 9 studies a range from $1.6 \%$ to $16 \%$ was found. The meta-analysis of proportions pointed out a $4.9 \%$ postoperative mortality rate $(95 \%$ CI $3.26-7.41)$. No heterogeneity was demonstrated $\left(\mathrm{I}^{2}=0 \% ; \mathrm{p}=0.58\right)$ (Fig. 2C).

Detailed data about recurrence, complications, and mortality rates are reported in Table 2.

\section{Metaregression analysis}

Metaregression analysis highlighted a trend towards a decrease of fistula recurrence over time with a $1 \%$ drop per year (Risk Ratio 0.989; 95\% CI 0.94-1.03), although this result was not significant $(\mathrm{p}=0.65)$. Bubble plot of metaregression is displayed in Additional file 1.

\section{Assessment of publication bias}

Egger's test of recurrence rate meta-analysis of proportions pointed out significant asymmetry $(\mathrm{p}=0.00006)$. P-curve estimates of 21 studies showed a $90 \%$ power of 


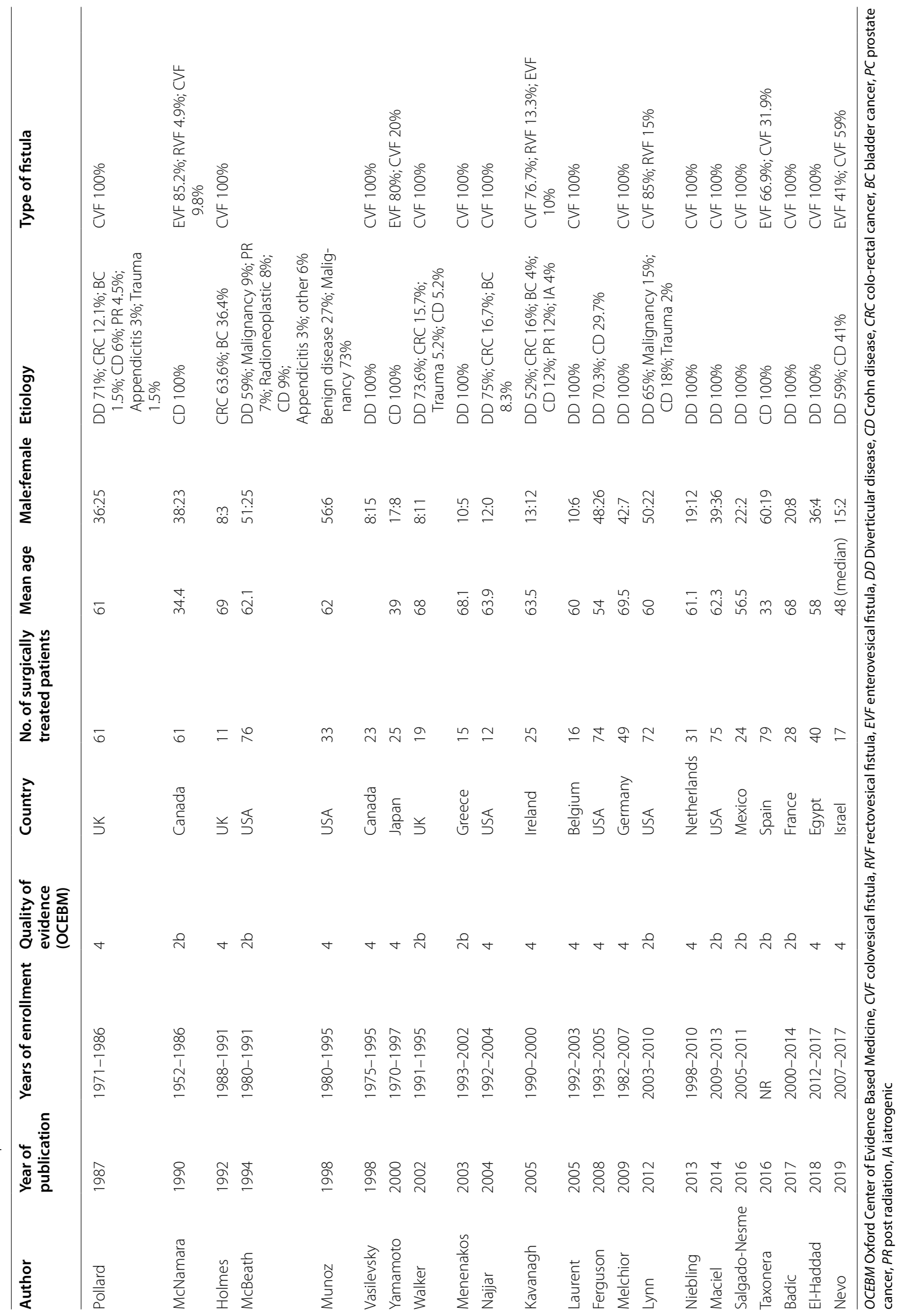




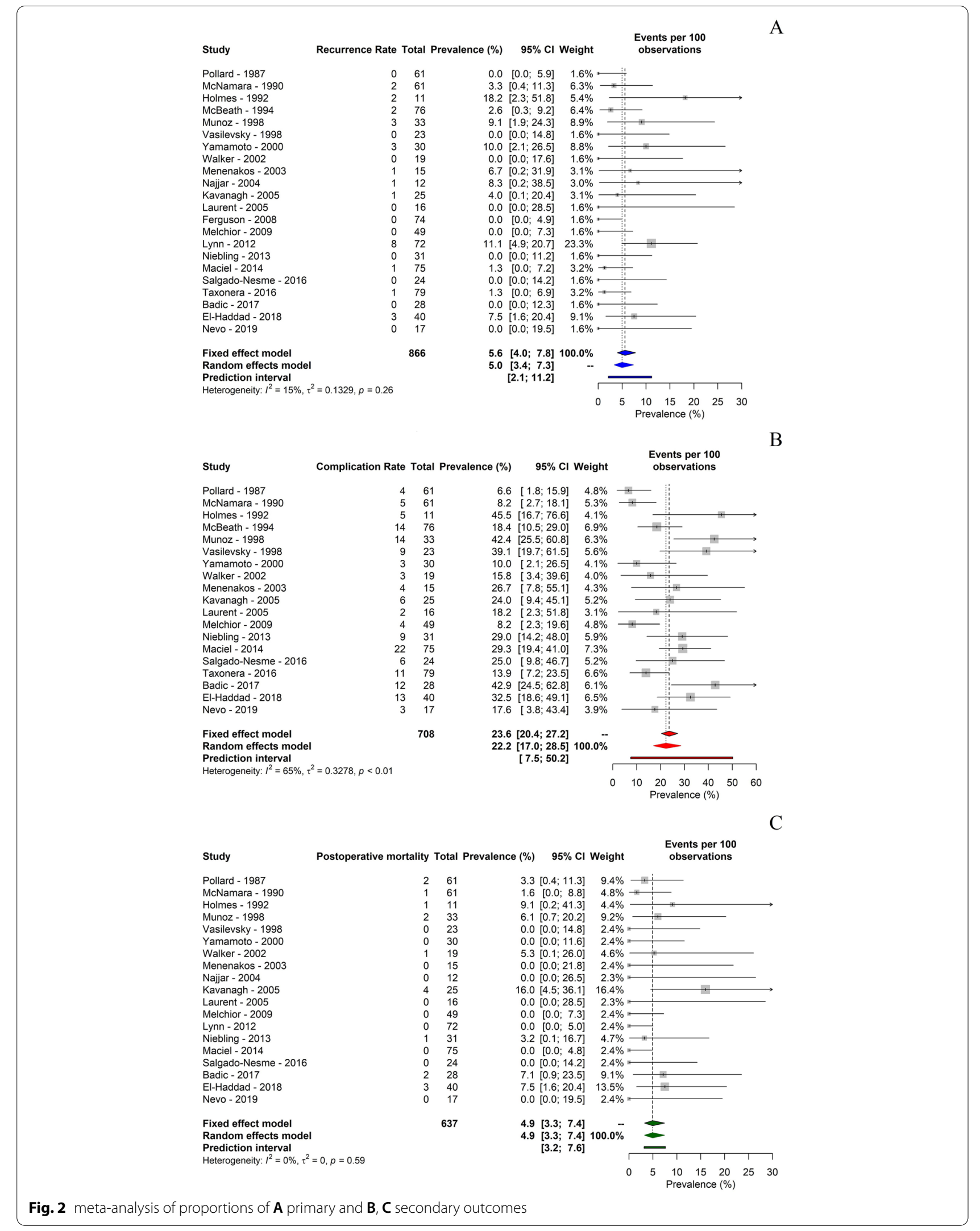

A 
Table 2 Recurrence, complications and postoperative mortality outcomes

\begin{tabular}{|c|c|c|c|c|c|}
\hline Author & $\begin{array}{l}\text { Median } \\
\text { follow-up } \\
\text { (months) }\end{array}$ & $\begin{array}{l}\text { Recurrence } \\
\text { rate }(\%)\end{array}$ & $\begin{array}{l}\text { Complication } \\
\text { rate }(\%)\end{array}$ & Complications (description) & $\begin{array}{l}\text { Postoperative } \\
\text { mortality (\%) }\end{array}$ \\
\hline Pollard & 195 (mean) & 0 & 6.5 & Cardiorespiratory complications 3.2; anastomotic leak 3.2\% & 3.2 \\
\hline McNamara & 106 (mean) & 3.3 & 8.2 & $\begin{array}{l}\text { Urine leak 3.2\%; enterocutaneous fistula 1.6\%; wound infection } \\
1.6 \%\end{array}$ & 1.6 \\
\hline Holmes & 13 & 18.2 & 45.5 & $\begin{array}{l}\text { Deep vein thrombosis 9.1\%; chest infection 27.3\%; pelvic } \\
\text { abscess } 9.1 \%\end{array}$ & 9.1 \\
\hline McBeath & 15.3 (mean) & 2.8 & 18.6 & $\begin{array}{l}\text { Anastomotic leak 5.7\%; small bowel obstruction } 2.8 \% \text {; ileus } \\
\text { 1.4\%; other } 8.7 \%\end{array}$ & NR \\
\hline Munoz & 34 & 9.1 & 42 & NR & 6 \\
\hline Vasilevsky & 30.8 & 0 & 40 & $\begin{array}{l}\text { Urinary tract infection } 9.5 \% \text {; atelectasis } 7.1 \% \text {; prolonged ileus } \\
4.8 \% \text {; arrhythmias } 4.8 \% \text {; other } 13.8 \%\end{array}$ & 0 \\
\hline Yamamoto & 159 & 10 & 10 & Anastomotic leak 6.7\%; intrabdominal abscess 3.3\% & 0 \\
\hline Walker & 35 & 0 & 15.7 & Urinary leak 5.3\%; wound infection 5.2\%; ischemic colitis 5.2\% & 5.2 \\
\hline Menenakos & 61.7 & 5.5 & 27.7 & $\begin{array}{l}\text { Anastomotic leak } 6.6 \% \text {; gastroparesis } 6.6 \% \text {; abdominal wall } \\
\text { hematoma 6.6\%; minor hemorrhage through the drain } 6.6 \%\end{array}$ & 0 \\
\hline Najjar & 2-108 (range) & 8.3 & NR & $\mathrm{NR}$ & 0 \\
\hline Kavanagh & 6 (mean) & 4 & 24 & $\begin{array}{l}\text { Acute renal failure 4\%; acute pulmonary oedema 4\%; atrial } \\
\text { fibrillation } 4 \% \text {; incisional hernia 4\%; wound infection 4\%; } \\
\text { anastomotic leak } 4 \%\end{array}$ & 16 \\
\hline Laurent & 64 (mean) & 0 & 18.2 & Pulmonary infection 9.1\%; postoperative hemorrhage 9.1\% & 0 \\
\hline Ferguson & 6.5 & 0 & NR & NR & NR \\
\hline Melchior & 68 & 0 & 8.2 & Pneumonia 6.1\%; wound infection 2\% & 0 \\
\hline Lynn & 31 & 11.1 & NR & NR & 0 \\
\hline Niebling & 129 & 0 & 29 & $\begin{array}{l}\text { Wound infection } 12.9 \% \text {; urinary tract infection } 6.5 \% \text {; abscess } \\
\text { formation } 6.5 \% \text {; anastomotic leak } 3.1 \%\end{array}$ & 3.2 \\
\hline Maciel & 8.8 (mean) & 1.3 & 29.3 & Colocutaneous fistula 2.6\%; & 0 \\
\hline Salgado-Nesme & 18.6 (mean) & 0 & & & 0 \\
\hline Taxonera & 101 & 1.3 & 13.9 & $\begin{array}{l}\text { Abdominal abscesses } 6.3 \% \text {; anastomotic leaks } 2.5 \% \text {; intestinal } \\
\text { obstruction 1.3\%; hemorrhage } 3.8\end{array}$ & NR \\
\hline Badic & 12 & 0 & 43 & $\mathrm{NR}$ & 7 \\
\hline El-Haddad & 21 & 7.5 & 32.5 & $\begin{array}{l}\text { Anastomotic leak } 7.5 \% \text {; parastomal hernia 5\%; colostomy } \\
\text { retraction 2.5\%; ileus 7.5\% }\end{array}$ & 7.5 \\
\hline Nevo & 49 & 0 & 18 & $\begin{array}{l}\text { Surgical site infection } 6 \% \text {; intra-abdominal abscess } 6 \% \text {; persis- } \\
\text { tent postoperative fever } 6 \%\end{array}$ & 0 \\
\hline
\end{tabular}

NR not reported

analysis (95\% CI 80-96\%) with a significant right skewness of the curve $(\mathrm{p}<0.001)$, underlining a "true" effect size behind our findings. Funnel plot of publication bias and P-curve analysis plot is shown in Fig. 3.

Further results are reported in Additional file 1.

\section{Surgical management}

In most of the studies, a one-stage laparotomic approach was performed. Eighteen studies reported the use of open surgery for a total of 637 patients. The laparoscopic approach was reported in only 7 studies for a total of 121 patients, with an average conversion rate to open surgery of $23 \%$. The study published by Maciel et al. was the only reporting robotic approach for the treatment of $20 \mathrm{CVF}$ patients; in their series, no need for conversion to open surgery was recorded [37].

Primary resection and anastomosis (one-stage procedure) was performed in 641 patients (75.5\%). A multistage strategy with curative intent, comprehensive of resection and primary anastomosis with colostomy and/ or Hartmann procedure (two-stage procedure) with later closure of the stoma (three-stage approach), was carried out in 132 patients (15.5\%). Interventions with palliative intent (i.e., definitive ileostomy or colostomy) were performed in 53 patients $(6.2 \%)$ mainly due to locally advanced/metastatic neoplastic disease or poor general conditions. Only one study, with a total of 23 patients, did not report details regarding the surgical approach [29]. 


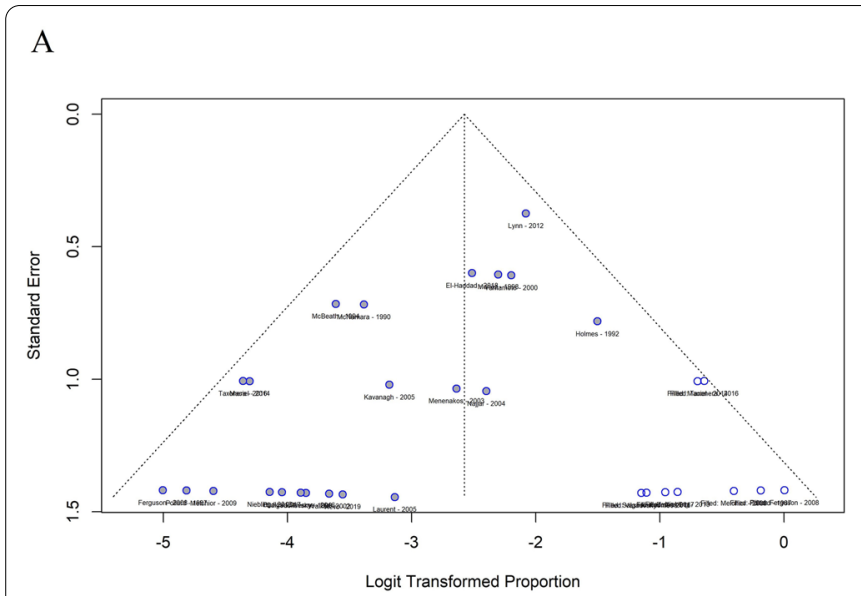

Fig. 3 A Funnel plot of publication bias; B P-curve analysis plot

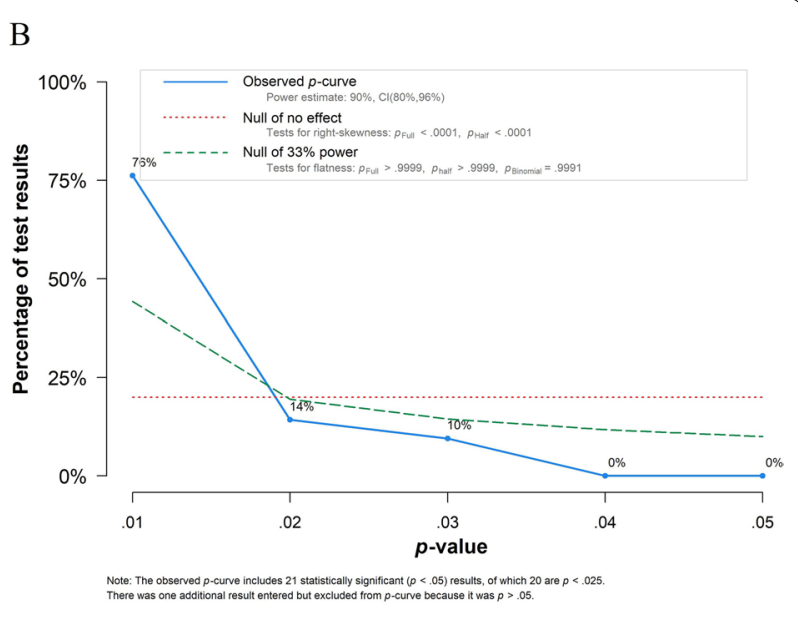

B
Seventeen studies described the surgical procedures performed on the bladder, providing data on 662 out of 849 patients. In 215 patients (32.4\%), minimal bladder surgery (i.e., simple blunt dissection, fistula division, omental interposition, debridement, curettage) was sufficient. On the other hand, direct repair (with suture or with mechanical stapler) was performed on 344 patients (51.9\%). Partial or radical cystectomy was indicated in a small proportion of patients, respectively 92 (13.8\%) and 19 (2.8\%) cases.

All of the studies reported the need for extensive vesical catheterization after surgery. Eleven of them reported a mean catheterization time of 9.2 days, ranging from 7 to 14 days. Further details are reported in Table 3.

\section{Discussion}

Managing entero-colovesical fistulas can be challenging. Much of our knowledge results from the opinions of few experts in the field, emerging from large case series rather than from trial settings. Consequently, there is a wide variation in the definitions of fistula location and complexity with little standardization of treatment protocols and outcome measures [42]. Since the closure rate of the fistula remains quite low after conservative treatment and due to the remarkable risk of septic complications following conservative treatment, all patients able to tolerate surgery, should be deemed surgical candidates. The lack of consensus on the if, when, and how to repair a fistula represents a crucial issue for surgeons and the development of standardized and well-structured protocols of treatment are unmet key needs, urgently required to ensure patient safety. An important consideration regards the choice of diverting stoma. Seventeen studies reported information regarding the type of ostomy. Colostomy was performed in 69 cases, whereas ileostomy in 19 cases. The proportion of the former was more than triple compared to the latter. This finding may be explained considering the greater proportion of diverticular disease-related fistulas. On the other hand, ileostomy was performed mainly as palliative treatment in the presence of frozen pelvis caused by radiation therapy or advanced cancer.

Kavanagh reported the highest mortality (four patients over $25-16 \%)$. All patients who died suffered from diverticular disease. A possible explanation for this finding would be the advanced age ( 80 years) of this subset of patients. Albeit not significant, metaregression analysis pointed out an inversely proportional correlation between recurrence rate and years of publication. This may reflect a progressive improvement in surgical techniques over time.

\section{Surgical management of the enteric tract}

The choice of the best surgical strategy relies on the underlying etiology of the fistula. In any case, the goal is the resection of the intestine/bowel segment involved in the fistula and the closure of the bladder. Surgical treatment options can be summarized as single-stage and multi-stages procedures. Due to the low mortality and similar postoperative morbidity rates compared to staged procedures, primary resection, and anastomosis (single-stage repair) should be considered the intervention of choice whenever feasible [5, 27]. A single-stage procedure was possible in more than $90 \%$ of the cases in 8 out of 21 studies of the present review. Among others, El-Haddad and Lynn reported the highest rates of multistages procedures, $52.5 \%$ and $39 \%$ respectively $[9,35]$. Although no differences between single- and multi-stage procedures in terms of fistula recurrence were observed, a two-stage repair (primary anastomosis with colostomy/ 


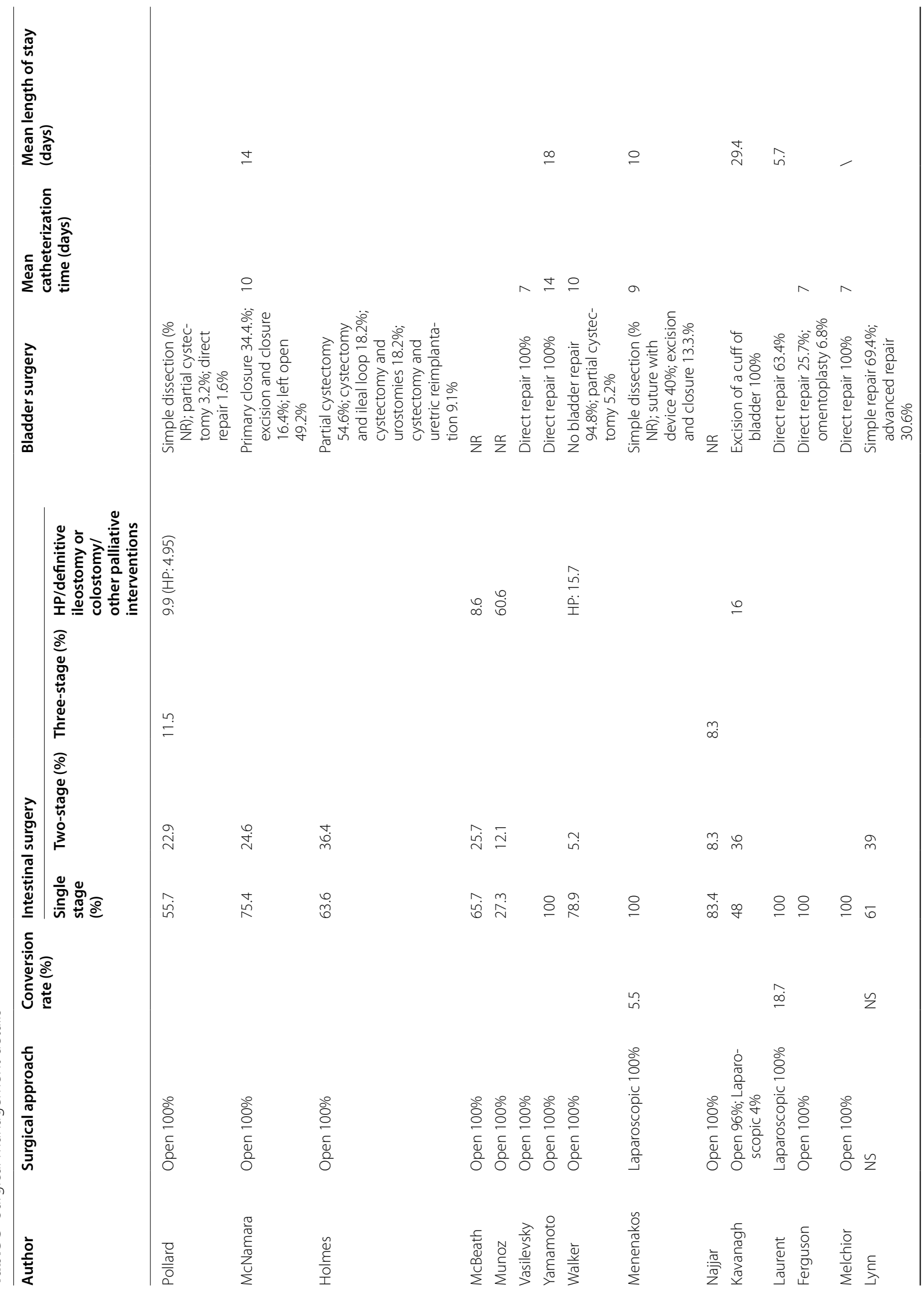




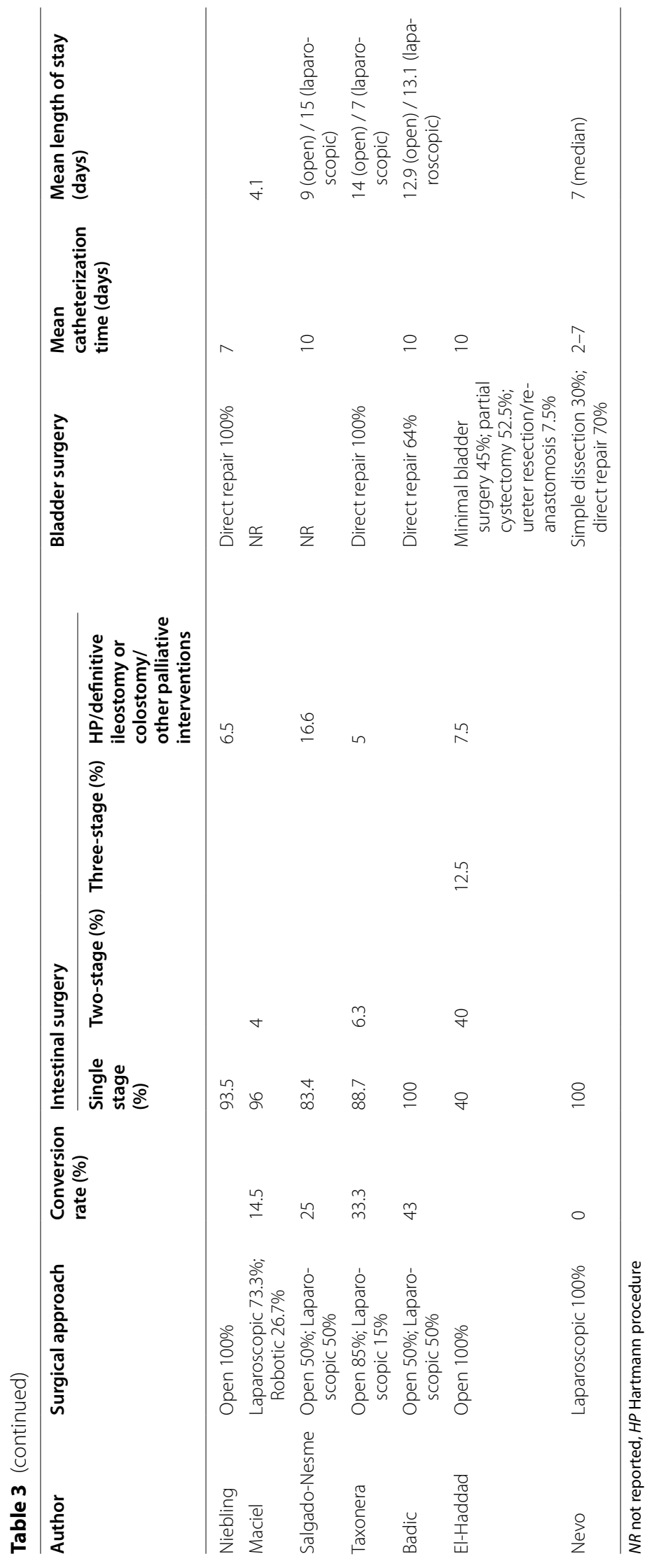


ileostomy or Hartmann procedure) was considered the optimal surgical strategy for patients with an inflammatory colon mass. Primary anastomosis with ileostomy should be also be thoroughly considered for CD patients, especially those presenting with ileo-vesical fistulas. This decision should also encompass risk factors associated with higher morbidity (perioperative steroid use, smoking, malnutrition), as well as the degree of inflammation/quality of surrounding tissues. Three-stages repair, characterized by defunctioning ostomy followed by resection-anastomosis and later closure of the stoma, was preferred in patients with pelvic abscess and poor performance status. A definitive diverting ileostomy or colostomy is mostly performed with palliative intent, it is rarely associated with fistula healing, and carries a high risk of persistent/recurrent urinary sepsis. Nevertheless, it can represent a valid strategy to relieve patients' symptoms. Other candidates for defunctioning stoma are represented radiation-induced fistula patients; due to the high risk of recurrence and intraoperative technical difficulties encountered in severe cases, this kind of surgery can sometimes represent the only treatment option [1].

Although open surgery remains the preferred approach to manage EVFs/CVFs, minimally invasive procedures have progressively been adopted in surgical practice. Laparoscopic surgery has been reported to have similar fistula recurrence rates and postoperative complications. In the present review, 7 studies for a total of 121 patients reported data of minimally invasive procedures. Most of them claim that laparoscopic surgery has been demonstrated safe and feasible in experienced hands, although the conversion rate remains remarkable [37]. In our analysis conversion to open surgery ranged from 5.5\% [32] to $33.3 \%$ [39] and an average complication incidence of $25.5 \%$ was computed.

\section{Surgical management of the bladder}

A great debate surrounding the optimum timing of repair, immediate or delayed, still exists. While the exact definition of what constitutes an "immediate" repair varies between studies, most authors consider less than 6 weeks appropriate. Intuitively, repair should be performed following a period of catheterization to allow the inflammation to settle and necrotic material to slough off whilst providing the opportunity for spontaneous closure[42]. A surgical repair of the bladder should not be routinely performed; indeed, according to Carpenter et al. in case of small fistulas, bladder catheterization alone might be sufficient [43]. In this regard, Walker et al. highlighted how the resection of the fistula with primary bowel anastomosis and bladder drainage alone resulted in no recurrences and low morbidity [31]. Similarly, Ferguson et al., in their series of 74 patients with EVFs of benign etiology, observed that indwelling Foley catheter placement alone is sufficient for bladder healing [34].

Available evidence suggests that, in case of large fistulas/overt defects into the bladder, a direct repair of the bladder wall with suture (single or double layer) shows favorable outcomes in terms of fistula recurrences and complication rates. In this case, simple suture, fistula curettage followed by suture, or omentum flap between bowel anastomosis and bladder represent valuable options [34]. Aggressive approaches such as partial or radical cystectomy as first-line treatment for EVF/CVFs should be considered only in case of infiltrating bladder cancer [44]. Indeed, in our analysis, only $10 \%$ and $3 \%$ of patients underwent partial and radical cystectomy respectively. The risk of fistula recurrence in bladder repair has been demonstrated to be four times greater in bladder wall resection as compared with primary repair [35]. The best timing for catheter removal is still debated, ranging from 7 to 14 days and mainly depending on bladder repair complexity and the primary cause of fistula occurrence.

\section{Strengths and limitations}

Other valuable systematic reviews previously published in the literature provided a comprehensive description of the diagnostic and therapeutic management of patients suffering from EVFs/CVFs. To the best of our knowledge, the present study is the first to focus specifically on surgical treatment of these patients and assessing recurrence, complications, and mortality rates through meta-analytic computations. Nevertheless, it is worth underlining some limitations. The quality of evidence was quite low, with all studies being retrospective. The diagnostic evaluation and follow-up of patients with enterovesical fistulas were heterogeneous across the included studies and only a minority of reports described the specific diagnosis, treatment, and scheduled imaging follow-up. Moreover, indications for surgical repair were either not reported or not standardized in most series and relied mainly on the surgeon's judgment. Finally, since most of the studies did not report separate outcome data for different surgical procedures nor different etiologies, the possibility to develop pair-wise comparisons as well as to explore the effect of clinically relevant variables on fistula recurrence was precluded.

\section{Conclusion}

In conclusion, our analysis has demonstrated that, although burdened by a non-negligible rate of complications, surgical repair of entero-colovesical fistula leads to favorable results in terms of primary healing. Our review offers opportunities for significant further research in this field. Future prospective studies with 
granular datasets should evaluate the benefits and harms of surgical treatment using standardized and well-scheduled diagnostic examinations in patients with suspicion of enterovesical fistulas.

\section{Abbreviations}

EVF: Enterovesical fistula; CVF: Colovesical fistula; RVF: Rectovesical fistula; CT: Computed tomography; MR: Magnetic resonance; CD: Crohn's disease; DD: Diverticular disease; CRC: Colorectal cancer; BC: Bladder cancer; PC: Prostate cancer; PR: Post radiation; IA: latrogenic; FUP: Follow-up; OCEBM: Oxford Center of Evidence Based Medicine.

\section{Supplementary Information}

The online version contains supplementary material available at https://doi. org/10.1186/s12893-021-01272-6.

Additional file 1. Supplemetary materials including diagnostic methods, results of sensitivity analysis, funnel plots and P-curve analysis for complications and postoperative mortality, bubble plot of metaregression, word combination syntax.

\section{Acknowledgements}

We would like to thank Prof. Ileana Nacca from The International School of Naples for the professional English language revision.

\section{Authors' contributions}

SG and FS designed the study; SG collected data, performed statistical analysis, and drafted the manuscript; FS, AB, SP, FB, IS, AC and MT collected data and participated in drafting the manuscript; $A G, A F, R C, S S, G D$, and $C C$ supervised the study. All authors read and approved the final manuscript.

\section{Funding}

The authors have not received support from any organization for the submitted work.

\section{Availability of data and materials}

The data and code that support the findings of this study are available from the corresponding author, upon reasonable request.

\section{Declarations}

\section{Ethics approval and consent to participate}

The present study is a systematic review of the literature and meta-analysis. Due to the retrospective nature of the study, a specific ethical approval was not deemed necessary.

\section{Consent for publication}

Not applicable.

\section{Competing interests}

The authors have no competing interest to declare that are relevant to the content of this article.

\footnotetext{
Author details

${ }^{1}$ General Surgery Unit, ASST Brianza, Vimercate Hospital, Via Santi Cosma e Damiano, 10, 20871 Vimercate, Italy. ${ }^{2}$ Unit of Urological Robotic Surgery and Renal Transplantation, Careggi Hospital, University of Florence, Largo Piero Palagi, 1, 50139 Florence, Italy. ${ }^{3}$ Department of Experimental and Clinical Medicine, University of Florence, Piazza di San Marco, 4, 50121 Florence, Italy. ${ }^{4}$ University of Milan, Via Festa del Perdono, 7, 20122 Milan, Italy. ${ }^{5}$ Urology Unit, ASST Brianza, Vimercate Hospital, Via Santi Cosma e Damiano 10, 20871 Vimercate, Italy. ${ }^{6}$ General Surgery Unit, ASST Fatebenefratelli-Sacco, Via Giovanni Battista Grassi, 74, 20157 Milan, Italy. ${ }^{7}$ Department of Medical Sciences, Gastroenterology Unit, Ospedali Riuniti di Foggia, Viale Luigi Pinto, 1, 71122 Foggia, Italy.
}

Received: 15 February 2021 Accepted: 21 May 2021

Published online: 27 May 2021

\section{References}

1. Golabek T, Szymanska A, Szopinski T, Bukowczan J, Furmanek M, Powroznik J, et al. Enterovesical fistulae: aetiology, imaging, and management. Gastroenterol Res Pract. 2013. https://doi.org/10.1155/2013/617967.

2. Pollard SG, Macfarlane R, Greatorex R, Everett WG, Hartfall WG. Colovesical fistula. Ann R Coll Surg Engl. 1987:9(4):163-5.

3. Morrison PD, Addison N V. A study of colovesical fistulae in a district hospital. Ann R Coll Surg Engl. 1983;65(4):221-3.

4. Smeenk RM, Plaisier PW, van der Hoeven JAB, Hesp WLEM. Outcome of surgery for colovesical and colovaginal fistulas of diverticular origin in 40 patients. J Gastrointest Surg. 2012. https://doi.org/10.1007/ s11605-012-1919-1.

5. Garcea G, Majid I, Sutton CD, Pattenden CJ, Thomas WM. Diagnosis and management of colovesical fistulae; six-year experience of 90 consecutive cases. Color Dis. 2006. https://doi.org/10.1111/j.1463-1318.2005. 00928.x.

6. Solkar MH, Forshaw MJ, Sankararajah D, Stewart M, Parker MC. Colovesical fistula-is a surgical approach always justified? Color Dis. 2005. https:// doi.org/10.1111/j.1463-1318.2005.00863.x.

7. Woods RJ, Lavery IC, Fazio VW, Jagelman DG, Weakley FL. Internal fistulas in diverticular disease. Dis Colon Rectum. 1988. https://doi.org/10.1007/ BF02556792.

8. Daniels IR, Bekdash B, Scott HJ, Marks CG, Donaldson DR. Diagnostic lessons learnt from a series of enterovesical fistulae. Color Dis. 2002. https:// doi.org/10.1046/j.1463-1318.2002.00370.x.

9. El-Haddad HM, Kassem MI, Sabry AA, Abouelfotouh A. Surgical protocol and outcome for sigmoidovesical fistula secondary to diverticular disease of the left colon: a retrospective cohort study. Int J Surg. 2018. https://doi. org/10.1016/j.ijsu.2018.05.742

10. Najjar SF, Jamal MK, Savas JF, Miller TA. The spectrum of colovesical fistula and diagnostic paradigm. Am J Surg. 2004. https://doi.org/10.1016/j. amjsurg.2004.08.016.

11. Kavanagh D, Neary P, Dodd JD, Sheahan KM, O'Donoghue D, Hyland JMP. Diagnosis and treatment of enterovesical fistulae. Color Dis. 2005. https:// doi.org/10.1111/j.1463-1318.2005.00786.x.

12. Melchior S, Cudovic D, Jones J, Thomas C, Gillitzer R, Thüroff J. Diagnosis and Surgical Management of Colovesical Fistulas Due to Sigmoid Diverticulitis. J Urol. 2009. https://doi.org/10.1016/j.juro.2009.05.022.

13. Tang YZ, Booth TC, Swallow D, Shahabuddin K, Thomas M, Hanbury $\mathrm{D}$, et al. Imaging features of colovesical fistulae on MRI. Br J Radiol. 2012;85(1018):1371-5. https://doi.org/10.1259/bjr/55871151.

14. Kirsh GM, Hampel N, Shuck JM, Resnick MI. Diagnosis and management of vesicoenteric fistulas. Surg Gynecol Obs. 1991;173(2):91-7.

15. Amin M, Nallinger R, Polk HC Jr. Conservative treatment of selected patients with colovesical fistula due to diverticulitis. Surg Gynecol Obs. 1984;159(5):442-4.

16. Moher D, Liberati A, Tetzlaff J, Altman DG, Altman D, Antes G, et al. Preferred reporting items for systematic reviews and meta-analyses: the PRISMA statement. PLoS Med. 2009. https://doi.org/10.1371/journal. pmed.1000097.

17. Shea BJ, Reeves BC, Wells G, Thuku M, Hamel C, Moran J, et al. AMSTAR 2: A critical appraisal tool for systematic reviews that include randomised or non-randomised studies of healthcare interventions, or both. BMJ. 2017. https://doi.org/10.1136/bmj.j4008.

18. Phillips B, Ball C, Sackett DL. Levels of Evidence and grades of recommendation. Oxford Cent Evid Based Med 1998. 2009.

19. Higgins JPT, Thompson SG, Deeks JJ, Altman DG. Measuring inconsistency in meta-analyses. Br Med J. 2003. https://doi.org/10.1136/bmj.327. 7414.557.

20. R Core Team. R: A Language and Environment for Statistical Computing Vienna, Austria. 2019. http://www.R-project.org/.

21. Schwarzer G, Carpenter JR, Rücker G. An Introduction to Meta-Analysis in R. 2015. https://doi.org/10.1007/978-3-319-21416-0_1.

22. Viechtbauer W. Conducting meta-analyses in $\mathrm{R}$ with the metafor. J Stat Softw [Internet]. 2010;36(3):1-48. https://www.jstatsoft.org/v36/i03. 
23. McGrath S, Sohn H, Steele R, Benedetti A. Meta-analysis of the difference of medians. Biometrical J. 2020. https://doi.org/10.1002/bimj.201900036

24. Harrer M, Cuijpers P, Furukawa T., Ebert DD. Doing Meta-Analysis in R: A Hands-on Guide. Prot Lab. 2019. https://doi.org/10.5281/zenodo.25518 03.

25. McNamara MJ, Fazio VW, Lavery IC, Weakley FL, Farmer RG. Surgical treatment of enterovesical fistulas in Crohn's disease. Dis Colon Rectum. 1990. https://doi.org/10.1007/BF02055467.

26. Holmes SAV, Christmas TJ, Kirby RS, Hendry WF. Management of colovesical fistulae associated with pelvic malignancy. Br J Surg. 1992. https://doi. org/10.1002/bjs.1800790520.

27. McBeath RB, Schiff M, Allen V, Bottaccini MR, Miller Jl, Ehreth JT. A 12-year experience withenterovesical fistulas. Urology. 1994. https://doi.org/10. 1016/S0090-4295(94)80200-9.

28. Muñoz M, Nelson H, Harrington J, Tsiotos G, Devine R, Engen D. Management of acquired rectourinary fistulas: outcome according to cause. Dis Colon Rectum. 1998. https://doi.org/10.1007/BF02258219.

29. Vasilevsky CA, Belliveau P, Trudel JL, Stein BL, Gordon PH. Fistulas complicating diverticulitis. Int J Colorectal Dis. 1998. https://doi.org/10.1007/ s003840050135.

30. Yamamoto T, Keighley MRB. Enterovesical fistulas complicating Crohn's disease: clinicopathological features and management. Int J Colorectal Dis. 2000. https://doi.org/10.1007/s003840000233.

31. Walker KG, Anderson JH, Iskander N, McKee RF, Finlay IG. Colonic resection for colovesical fistula: 5-year folow-up. Color Dis. 2002. https://doi. org/10.1046/j.1463-1318.2002.00353.x.

32. Menenakos E, Hahnloser D, Nassiopoulos K, Chanson C, Sinclair V, Petropoulos P. Laparoscopic surgery for fistulas that complicate diverticular disease. Langenbeck's Arch Surg. 2003. https://doi.org/10.1007/ s00423-003-0392-4.

33. Laurent SR, Detroz B, Detry O, Degauque C, Honoré P, Meurisse M. Laparoscopic sigmoidectomy for fistulized diverticulitis. Dis. Colon Rectum. 2005. https://doi.org/10.1007/s10350-004-0745-2.

34. Ferguson GG, Lee EW, Hunt SR, Ridley CH, Brandes SB. Management of the bladder during surgical treatment of enterovesical fistulas from benign bowel disease. J Am Coll Surg. 2008. https://doi.org/10.1016/j. jamcollsurg.2008.05.006.

35. Lynn ET, Ranasinghe NE, Dallas KB, Divino CM. Management and outcomes of colovesical fistula repair. Am Surg. 2012. https://doi.org/10 1177/000313481207800529.
36. Niebling $M$, Van Nunspeet $L$, Zwaving $H$, Eddes EH, Bosker R, Eeftinck Schattenkerk M. Management of colovesical fistulae caused by diverticulitis: 12 years of experience in one medical centre. Acta Chir Belg. 2013. https://doi.org/10.1080/00015458.2013.11680881

37. Maciel V, Lujan HJ, Plasencia G, Zeichen M, Mata W, Jorge I, et al. Diverticular disease complicated with colovesical fistula: laparoscopic versus robotic management. Int Surg. 2014. https://doi.org/10.9738/INTSU RG-D-13-00201.1.

38. Salgado-Nesme N, Vergara-Fernández O, Espino-Urbina LA, Luna-Torres HA, Navarro-Navarro A. Advantages of minimally invasive surgery for the treatment of colovesical fistula. Rev Invest Clin. 2016;68(6):229-304.

39. Taxonera C, Barreiro-de-Acosta M, Bastida G, Martinez-Gonzalez J, Merino O, García-Sánchez V, et al. Outcomes of medical and surgical therapy for entero-urinary fistulas in Crohn's disease. J Crohn's Colitis. 2016. https:// doi.org/10.1093/ecco-jcc/jjw016..

40. Badic B, Leroux G, Thereaux J, Joumond A, Gancel CH, Bail JP, et al. Colovesical fistula complicating diverticular disease: a 14-year experience. Surg Laparosc Endosc Percutaneous Tech. 2017. https://doi.org/10.1097/ SLE.0000000000000375.

41. Nevo Y, Shapiro R, Froylich D, Meron-Eldar S, Zippel D, Nissan A, et al. Over 1-year followup of laparoscopic treatment of enterovesical fistula. J Soc Laparoendosc Surg. 2019. https://doi.org/10.4293/JSLS.2018.00095.

42. Hillary CJ, Osman NI, Hilton P, Chapple CR. The aetiology, treatment, and outcome of urogenital fistulae managed in well- and low-resourced countries: a systematic review. Eur Urol 2016. https://doi.org/10.1016/j. eururo.2016.02.015.

43. Carpenter WS, Allaben RD, Kambouris AA. One-stage resections for colovesical fistulas. J Urol. 1972. https://doi.org/10.1016/S0022-5347(17) 60706-7.

44. de Moya MA, Zacharias N, Osbourne A, Butt MU, Alam HB, King DR, et al. Colovesical fistula repair: is early foley catheter removal safe?. J Surg Res. 2009. https://doi.org/10.1016/j.jss.2009.03.094.

\section{Publisher's Note}

Springer Nature remains neutral with regard to jurisdictional claims in published maps and institutional affiliations.
Ready to submit your research? Choose BMC and benefit from:

- fast, convenient online submission

- thorough peer review by experienced researchers in your field

- rapid publication on acceptance

- support for research data, including large and complex data types

- gold Open Access which fosters wider collaboration and increased citations

- maximum visibility for your research: over $100 \mathrm{M}$ website views per year

At BMC, research is always in progress.

Learn more biomedcentral.com/submissions 